\title{
Estudos Críticos da Paz e Crime Organizado Transnacional
}

Critical Studies on Peace and Transnational Organized Crime

Études Critiques de la Paix et Crime Organisé Transnational

Marcos Alan S. V. Ferreira

\section{OpenEdition}

\section{Journals}

Edição electrónica

URL: http://journals.openedition.org/rccs/6643

DOI: $10.4000 /$ rccs. 6643

ISSN: 2182-7435

\section{Editora}

Centro de Estudos Sociais da Universidade de Coimbra

Edição impressa

Data de publição: 1 Setembro 2017

Paginação: 29-50

ISSN: 0254-1106

Refêrencia eletrónica

Marcos Alan S. V. Ferreira, «Estudos Críticos da Paz e Crime Organizado Transnacional », Revista Crítica de Ciências Sociais [Online], 113 | 2017, colocado online no dia 27 julho 2017, criado a 01 maio 2019. URL : http://journals.openedition.org/rccs/6643; DOI : 10.4000/rccs.6643 


\title{
MARCOS ALAN S. V. FERREIRA
}

\section{Estudos Críticos da Paz e Crime Organizado Transnacional}

\begin{abstract}
Este artigo visa entender como conceitos centrais dos Estudos para a Paz (EP), em particular em sua vertente crítica, podem ser úteis na compreensão analítica das mazelas do Crime Organizado Transnacional (COT). O artigo começa por explorar as diferenças entre os EP em suas vertentes convencionais e críticas, analisando em seguida o modo como o COT se constitui como uma ameaça difusa à paz que afeta sociedades tanto em conflito, como estabilizadas. Depois reexamina algumas categorias e marcos conceituais dos EP à luz da problemática do COT, confrontando outros trabalhos e mostrando suas limitações na compreensão do crime organizado. Esta estrutura de reflexão nos permitirá debater possibilidades analíticas críticas que abarquem uma explicação consistente sobre a problemática do COT à luz da conceituação de violência proposta por Johan Galtung.
\end{abstract}

Palavras-chave: crime organizado; drogas; Estudos para a Paz; redes ilícitas; violência.

\section{Introdução}

Em uma breve análise sobre a mudança da natureza dos conflitos armados na última década, Jordan Ryan, então Diretor Executivo do Escritório para a Prevenção e Recuperação de Crises do Programa das Nações Unidas para o Desenvolvimento (PNUD), afirmou em 2013 um dado alarmante: para cada morte em uma guerra em andamento, há outras nove relacionadas com violências entre gangues e crime organizado (Ryan, 2013). Este índice decorre de uma complexa conjuntura que mistura crime local e transfronteiriço, exclusão socioeconômica, rápida urbanização e em alguns casos disputas de território ou identitárias (Wennmann, 2015: 1).

Neste contexto, ainda que a violência política que visa mudar a balança de poder em dado território ou região continue a ser uma preocupação vide, por exemplo, os conflitos atuais na Síria, República Democrática do Congo, entre outros -, é inegável que atualmente nos confrontamos com uma explosão da violência social e um aumento acentuado da violência 
criminal (Imbusch et al., 2011). Tão grave é o problema, que em 2010 o Conselho de Segurança das Nações Unidas (CS-ONU) reconheceu oficialmente que o crime organizado é uma ameaça potencial à estabilidade, o que justificaria uma integração do Crime Organizado Transnacional (COT) nas análises de conflitos e no planejamento das outras atividades conduzidas pela Secretaria-geral do órgão (CS-ONU, 2010).

Diante desta conjuntura é surpreendente notar que o campo do conhecimento que se debruça em primeiro lugar sobre a análise dos conflitos, a violência e o estabelecimento de uma paz sustentável - os Estudos para a Paz (EP) ou Investigação para a Paz (Peace and Conflict Studies/ Research) - ainda conte com poucos estudos sistemáticos que visam compreender a correlação entre o COT e seus impactos na promoção da paz. Exceções aqui devem ser feitas às análises sobre criminalidade presentes em contextos pós-conflito ou após operações de paz da ONU, como os estudos de relevância publicados por Cockayne e Lupel (2011) e Kemp et al. (2016).

No entanto, o problema se torna mais complexo quando se consideram sociedades ditas "pacíficas", ou seja, aquelas em que não há grupos beligerantes organizados lutando pelo controle político de determinados territórios. Tal é o caso do Brasil, África do Sul e Venezuela, países que contam com índices alarmantes de homicídios, que encabeçam as estatísticas internacionais de violência armada, mas que não se configuram como sociedades em guerra (Seguridad Justicia y Paz, 2015). Por consequência, ainda que muito longe da proclamada paz, tais países são negligenciados nos estudos sobre a relação entre paz e criminalidade.

Perante essa problemática, este ensaio teórico-conceitual objetiva levantar possibilidades de debates que possam contribuir para preencher a lacuna existente no que se refere à inter-relação entre paz e COT. Entende-se aqui que a riqueza conceitual dos EP pode lançar luz sobre uma temática complexa, multifacetada e de natureza transdisciplinar. Consequentemente, poderá auxiliar a compreender o modo como os Estudos Críticos da Paz (ECP) ajudam a entender o COT enquanto resultado da injusta estrutura social, e simultaneamente enquanto agente estruturante de violência que impacta na qualidade da paz.

O presente artigo está estruturado em três partes, além da introdução e das considerações finais. Suas seções buscam sistematicamente explorar a ideia de que uma crítica teórica social deve estar ancorada em quatro pontos conforme descritos por Calhoun (1995:35) e seguidos também por Jutila et al. (2008: 630), quando estes últimos se referem aos EP, a saber: a) deve estar engajado com o mundo contemporâneo, reconhecendo seu 
estado de coisas e oferecendo perspectivas positivas de mudança; b) deve ter uma abordagem crítica da história e das condições culturais que operam a atividade acadêmica; c) deve ter um contínuo reexame crítico das categorias constitutivas e dos marcos conceituais de compreensão teórica, incluindo aí a construção histórica destes marcos; e d) implica confrontar com outros trabalhos de explicação social e mostrar as razões por trás das áreas cegas e dos mal-entendidos. É com essas premissas que se constroem os pressupostos dos ECP rumo a um resgate das premissas inovadoras de criticidade que deram origem ao campo.

Na subsequente seção serão analisadas criticamente as "condições culturais que operam a atividade acadêmica" (Calhoun, 1995: 35), explorando as diferenças entre os $\mathrm{EP}$ em suas vertentes convencionais e críticas. Isso nos permitirá compreender as limitações da vertente convencional para explicar o fenômeno contemporâneo do COT, entraves estes criados a partir de uma normalização científica que fragmentou os pressupostos ontológicos e epistemológicos deste campo do conhecimento. Buscando dar cabo ao primeiro ponto sugerido por Greg Calhoun (1995) acima descrito, na seção seguinte será explorado como o COT se constitui como ameaça difusa à paz que afeta sociedades diversas, estejam elas em conflito ou pós-conflito, sejam democráticas ou estabilizadas. Além disso, o COT tem características distintas do conflito tradicional e se beneficia da facilitação econômica e tecnológica gerada pelo processo de globalização. Na parte que antecede as considerações finais, o foco será nos dois pontos conclusivos de uma crítica teórica social sob os moldes de Calhoun (1995): reexaminar algumas categorias e marcos conceituais dos EP à luz da problemática do COT e confrontar outros trabalhos, mostrando suas limitações e áreas cinzentas no entendimento do fenômeno examinado neste artigo. Esta estrutura de reflexão nos permitirá debater possibilidades analíticas críticas que abarquem uma explicação consistente sobre a problemática do COT, em especial quando se leva em conta o conceito de violência proposto por Johan Galtung.

\section{Estudos para a Paz: por uma criticidade diante da normalidade científica}

Embora os anos 1930 e 1940 vissem uma onda crescente de estudos preocupados com a questão da paz nas ciências humanas (ver Wiberg, 2005), seria na década de 1950 e 1960 que se testemunharia um aumento drástico das investigações sistemáticas sobre a paz. A dinâmica da Guerra Fria, somada ao temor do retorno de uma guerra mundial e a novos ataques nucleares, fizeram com que uma gama de cientistas sociais refletissem mais profundamente sobre como promover a paz de maneira consistente e contínua. Foi nesse ínterim que surgiu nos Estados Unidos da América e na Europa 
uma onda crescente de departamentos e núcleos de pesquisa voltados para a compreensão da paz e dos conflitos, nos quais teóricos como Johan Galtung (fundador do Peace Research Institute of Oslo), Anatol Rapoport (Universidade de Michigan) e Kenneth Boulding (Universidade de Stanford) propuseram oferecer uma saída sã às alternativas realistas dos apóstolos da dissuasão nuclear e da Guerra Fria (Young, 2013: 168).

É deste engajamento de cientistas sociais norte-americanos e europeus que surgem os Estudos para a Paz. Peter Wallensteen, um dos mais engajados pesquisadores destes movimentos desde 1970, resume de maneira concisa o que é esse campo do conhecimento, como ele caminha e o que examina. Segundo ele,

o objetivo dos Estudos [ou Investigações] para a Paz é compreender as causas da violência e encontrar maneiras de reduzir ou acabar com essa violência. [...] A Investigação para a Paz é também sensível a mudanças históricas e circunstâncias locais, embora não só possa, como deva, manter a sua autonomia e orientação principal. Por vezes, as mudanças sociais constituem desafios aos paradigmas existentes de Investigação para a Paz e conduzem a novos campos de investigação. (Wallensteen, 2001: 3, grifos meus)

Como visto acima, o objetivo inicial dos EP era o de compreender as causas da violência. Mais além, a ideia era ver a guerra como um problema real que afeta a humanidade e que, por sua vez, necessitava de um estudo sistemático e rigoroso para encontrar caminhos para a paz (Jutila et al., 2008: 626). Neste sentido, a disciplina nasceu como crítica teórica e social, na medida em que questionava a normalidade da guerra e as premissas realistas de que o balanço de poder e os interesses nacionais prevalecem em detrimento da promoção da paz.

No entanto, posteriormente, notou-se um desvirtuamento das premissas que engendraram esse campo. Os EP gradualmente saíram de uma postura crítica para uma ciência normal institucionalizada (ver Kuhn, 1998: 44-45). Seus principais veículos como o Journal of Peace Research e o Journal of Conflict Resolution passaram de uma ciência reflexiva, aberta a construir novos paradigmas na construção de um mundo mais pacífico, para uma ciência burocrática, institucionalizada, focalizada mais na resolução de problemas técnicos e metodológicos (problem-solving) do que na análise reflexiva dos explanans da violência e dos desafios à paz (Jutila et al., 2008; Cravo e Pureza, 2005). Adicionalmente, ainda que não se coloquem como realistas, o paradigma dos EP replicam uma resposta pouco inovadora a essa corrente. Em vez de prevenir a guerra - como pressupõe o realismo - 
os EP convencionais vão mais além, com um desejo de erradicar a guerra, de maneira similar ao neoliberalismo institucional (Dahl, 2012: 257).

Ainda que os paradigmas prevalecentes em um dado campo adquiram seu status porque "são mais bem-sucedidos que seus competidores na resolução de alguns problemas que os cientistas reconhecem como graves" (Kuhn, 1998: 44), a normalização dos EP como ciência trouxe consigo duas fragmentações que desvirtuam as premissas ontológicas e epistemológicas ${ }^{1}$ que impulsionaram seu surgimento.

A primeira fragmentação foi ao nível de análise em que sua investigação opera. Ao explicar o que chama de mainstream peace science, Elizabeth Dahl diz que "dado que as guerras têm sido travadas tradicionalmente entre Estados, os Estudos para a Paz convencionais também tendem a ser mais estatocêntricos por natureza, procurando analisar e reduzir a violência organizada letal" (Dahl, 2012: 256). Isso fragmentou o objeto de pesquisa, que deixa de ser a manifestação da violência em seus múltiplos níveis como obstáculos à paz, para logo se concentrar no Estado. Esta fragmentação dos EP convencionais trouxe uma contradição com a própria ontologia destes estudos, na disciplina em que a premissa central é que a paz é a ausência ou redução da violência (Galtung, 1996; Wallensteen, 2001), o nível de análise deixa de examinar as causas mais amplas dos obstáculos à paz para se debruçar quase que exclusivamente na violência entre Estados ou a existência de guerra civil. Negligencia-se aqui que a violência se manifesta em diferentes níveis, desde o local até ao global e que a guerra é apenas uma das formas de violência. Ainda mais, a natureza da violência atual pode se

\footnotetext{
${ }^{1}$ No que tange à ontologia dos Estudos para a Paz, Demola Akinyoade (2012: 6-7) afirma que "a erudição, a pesquisa e a prática em Estudos sobre Paz e Conflitos se concentram em certas questões fundamentais, que definem a ontologia e da qual decorrem questões epistemológicas, metodológicas e teóricas da área. A mais básica destas questões é o que é a paz; a natureza, causas, manifestação, e dinâmica do conflito; os meios para a resolução de conflitos; a construção de uma paz sustentável. [...] Alguns dos conceitos-chave próprios da área são conflitos armados, grupos armados, resolução de conflitos, paz, consolidação da paz, manutenção da paz, pacificação, violência e guerra [...]. É sobre estes conceitos-chave e suas variantes que o campo de Estudos sobre Paz e Conflitos faz suas reivindicações ontológicas”. Já quanto à epistemologia dos Estudos para a Paz, Hakan Wiberg (2005: 26-27) ilustra que "Johan Galtung [...] propõe uma epistemologia mais geral [...] quando compara a Investigação para a Paz à Arquitectura ou à Medicina, por exemplo, cada uma das quais compreende um triângulo completo, composto por dados, teoria e valores (paz, saúde, beleza, etc. - tornando-se de seguida necessário especificar cada um dos vários aspectos). Algumas áreas do Direito, da Ética ou da Teologia ocupam-se de apenas um dos vértices: o das normas e valores. Certos domínios da ciência ou das Ciências Sociais centram-se exclusivamente num segundo vértice, desenvolvendo aspectos de conceptualização e de teoria, enquanto outras áreas se debruçam por inteiro sobre o terceiro vértice, coligindo e analisando dados ao mesmo tempo que crêem ser outros a ficar com a especulação teórica ('crêem', já que alguma teoria subjaz sempre às medições de que resultam os dados). [...] O modelo ideal de Investigação para a Paz apresentado por Galtung correlaciona os três vértices do triângulo: valores, teoria e dados”.
} 
dar de maneira distinta do modelo tradicional de guerra entre dois grupos beligerantes. Atores não estatais difusos, sem objetivos políticos claros e economicamente motivados, também podem ser promotores impactantes de violência dentro de uma dada sociedade. Assim, ao focalizarem principalmente o Estado, os EP convencionais mudam o eixo central do que fundamentou a criação do seu campo de estudo. Mais preocupante, deixa de lado o exame de fenômenos violentos que afetam a paz social e que não tem natureza estatal, tal como é o exemplo da atuação de atores não estatais transnacionais ligados à criminalidade ou ao terrorismo.

Uma segunda fragmentação - que é consequência da primeira - é o foco excessivo na paz negativa em detrimento da paz positiva. Como trazido por Johan Galtung e largamente disseminado no campo de EP tanto convencionais como críticos, a paz pode se dividir em duas tipologias: a paz positiva e a paz negativa. ${ }^{2}$ A paz negativa consiste na ausência de violência direta. Por sua vez, a violência direta pressupõe a existência clara de um sujeito executor de ato que não só impeça um indivíduo ou uma sociedade de alcançar algo, mas também busque causar danos ou destruição aos mesmos (Galtung, 1969: 169). Exemplificando, o fim de uma guerra interestatal configura o cessar da violência direta entre grupos beligerantes e, por sua vez, resultaria na paz negativa; um cessar-fogo entre dois grupos beligerantes dentro de um estado também se enquadraria nesta reflexão.

Porém, a ausência de violência direta pode se dar de maneira imposta por determinado ator político ou por atores não estatais através de formas diversas de opressão econômica e política. Assim, torna-se importante a definição do conceito de paz positiva. A paz positiva pressupõe a ausência ou redução de violência estrutural (Galtung, 1996: 9). Isto significa uma busca constante por qualidade de vida, crescimento pessoal, liberdade, igualdade social, equidade econômica, solidariedade, autonomia e participação (Galtung, 1969: 173). Ou seja, a ausência ou drástica redução de violência estrutural implica altos padrões de justiça social em uma dada sociedade. Desta maneira, ainda que seja um ideal difícil de alcançar, a plenitude da paz pode ser buscada com uma redução da violência estrutural. Considerando que a ausência de violência

\footnotetext{
${ }^{2}$ Há um incipiente debate que busca redefinir o conceito clássico de paz trazido por Galtung com suas tipologias positiva e negativa. Peter Wallensteen é um dos defensores dessa redefinição com o seu debate de "qualidade da paz" (quality peace). Como afirmado por ele, "A qualidade da paz é um conceito que quebra a dicotomia entre paz negativa versus positiva, há tempos dada por garantida. Esse conceito simplesmente diz que a paz tem de apresentar uma qualidade, para além da ausência de guerra (a típica definição de paz negativa), ficando por especificar quais são os elementos críticos dessa qualidade" (Wallensteen, 2015:3). Embora focado em condições de pós-guerra, as implicações do inovador debate de Wallensteen abre possibilidades de análise quanto à sua aplicação do conceito de qualidade da paz em casos de democracias que vivem cenários violentos.
} 
estrutural pressupõe padrões elevados de justiça social, a mensuração desta injustiça é fator central para compreender o rumo da paz em um contexto social.

Nota-se que ao focalizar especialmente o nível do Estado, o foco dos EP passou a dar demasiada importância à paz negativa, fragmentando o conceito que é central para o surgimento dos EP e negligenciando a existência da violência estrutural e cultural. Por outro lado, os Estudos Críticos da Paz continuam a trazer a importância de se compreender os caminhos para a aproximação da paz positiva. Esta ênfase colocada na paz positiva e negativa seria uma das diferenças centrais entre o mainstream e os ECP (Dahl, 2012: 258). No que se refere à perspectiva crítica, Johan Galtung comenta que os ECP comparam "a realidade empírica (dados) com os valores, tentando [...] mudar a realidade se esta não está em concordância com os valores - sendo os valores mais fortes do que os dados", enquanto os estudos empíricos para a paz são as ciências sociais mainstream (Galtung, 1996: 10). Dentre estes valores estão a cuidadosa consideração dos valores de justiça social e igualdade. Logo, diferente dos EP convencionais que são mais focalizados no nível do Estado,

[...] também deve prestar-se atenção às 'estruturas subjacentes' (econômicas, políticas e ideológicas) que sustentam ciclos de opressão e dominação a longo prazo. A injustiça deve ser confrontada de forma direta, garantindo-se defesa e trabalho constantes junto dos mais desfavorecidos. (Dahl, 2012: 257)

Ao lidar com as estruturas subjacentes, os ECP pressupõem que a paz negativa entendida como a ausência da guerra dentro ou entre Estados pode encobrir injustiças mais profundas que podem, por sua vez, desencadear posteriormente conflitos violentos (Cravo e Pureza, 2005: 9). Logo, a realização da paz positiva e negativa passa por abordar também a violência de maneira ampla, passando pela indireta, direta, cultural e estrutural para forjar uma paz justa e sustentável para todos (Senehi e Byrne, 2011: 398). Consequentemente, os ECP estão preocupados com a qualidade e natureza da paz não só ao nível do Estado, mas também em termos culturais, sociais, econômicos e políticos, o que abrange desde o sistema internacional, o Estado até à sociedade civil e ao nível local (Richmond, 2010).

Com base nos pressupostos acima, entende-se aqui a necessidade de uma revisão crítica que reconstrua o que foi fragmentado e que permita a consecução de pesquisas com diferentes níveis de análise, considerando não só a paz como ausência de violência direta, como também de violência 
estrutural e cultural. ${ }^{3}$ Esta abordagem crítica dos EP demanda do analista um manejo não só de ferramentas metodológicas e conceituais das Relações Internacionais e Ciência Política, como também uma transdisciplinaridade que permita dialogar entre aqueles campos e os da sociologia, antropologia e economia, e talvez até além.

Por fim, é necessária uma "redefinição das tarefas da Investigação para a Paz e, em particular, novas ideias teóricas que levem em consideração as lições ético-políticas e metodológicas aprendidas nas décadas passadas" (Patomäki, 2001: 723). Adicionalmente, Cravo e Pureza afirmam que

os Estudos para a Paz têm agora que radicalizar a sua abordagem crítica, assumindo a parcialidade e imperfeição dos conceitos que subjazem à modernidade ocidental e abrir-se, consequentemente, à heterogeneidade, à pluralidade, à periferia e aos contributos das epistemologias feministas, ambientais e dos estudos culturais. A descolonização do seu conhecimento e o horizonte da paz sustentável anunciam-se como as mediações necessárias desse retorno à vocação crítica. (2005: 17-18)

Com base nestes pressupostos e dentro das limitações do autor, espera-se que, ao examinar a questão do Crime Organizado Transnacional (COT) sob a ótica dos ECP, este artigo apresente as limitações de uma abordagem convencional estatocêntrica e focalizada no fenômeno da guerra. Este convencionalismo, por sua vez, frequentemente negligencia a manifestação da violência criminal como obstáculo central para a paz, tal como exemplificado nas periferias assoladas pelo crime organizado.

\section{Crime Organizado Transnacional como ameaça à paz}

O acelerado processo de globalização econômica e comunicacional após a queda do bloco soviético levou a um aumento do fluxo de bens e pessoas

\footnotetext{
${ }^{3}$ Galtung afirmaria que os conceitos de violência direta e estrutural se complementam com a ideia de violência cultural. Este conceito seria desenvolvido posteriormente, dado que o autor compreende que nem a conceituação de violência direta, nem a de violência estrutural explicaria uma tipologia relacionada com símbolos culturais. Como definido pelo próprio autor, "por violência cultural nos referimos a aqueles aspectos da cultura, da esfera simbólica de nossa existência - exemplificada pela religião e ideologia, linguagem e arte, ciência empírica e ciência formal (lógica, matemática) - que pode ser usada para justificar ou legitimar a violência direta ou estrutural. Estrelas, cruzes e crescentes; bandeiras, hinos e paradas militares; a onipresença do retrato do líder; discursos inflamados e pôsteres - tudo isso vem à mente [no conceito de violência estrutural]" (Galtung, 1990: 291). Ideia similar é desenvolvida pelo sociólogo francês Pierre Bourdieu em seu conceito de violência simbólica. No entanto, seu conceito difere do de violência estrutural em termos de aplicabilidade e campo. Enquanto Galtung está preocupado exclusivamente em compreender a violência como um desafio para alcançar a paz, Bourdieu está considerando de uma maneira ampla a questão do poder dentro da sociedade. Para mais sobre o assunto, ver Bourdieu (1989).
} 
para diferentes finalidades. Em tal contexto, não foram apenas as atividades legais e os processos de integração que ganharam impulso, mas também atividades diversas de cunho ilícito e com forte impacto na violência letal em diferentes locais do globo. Neste ínterim, grupos criminosos passaram a aproveitar a abertura das comunicações e a facilitação das transações financeiras para levarem adiante atividades ilícitas que provocaram um aumento do tráfico de drogas, armas e tráfico de seres humanos (Zabyelina, 2009: 11). Tais atividades passaram a colocar em oposição diferentes gangues e grupos com interesses conflitantes, que ao lutarem entre si e contra o Estado geram um número crescente de mortes violentas. A alta taxa de mortes violentas está intimamente ligada ao crime organizado, bem como à facilidade na obtenção de armas através do comércio ilegal transfronteiriço (UNDP, 2013: 44). Este problema encontra-se interligado com outro fenômeno global, os narcóticos internacionais e o tráfico de seres humanos (UNDP, 2013).

Diante desse contexto, como se pode definir Crime Organizado Transnacional? Um "grupo criminoso organizado" é definido pelo artigo 2. da Convenção das Nações Unidas contra o Crime Organizado Transnacional (2000) como um grupo estruturado de três ou mais pessoas, existindo por um período de tempo e atuando em conjunto com o objetivo de cometer um ou mais crimes graves para obter direta ou indiretamente benefícios materiais ou financeiros (ONU, 2000). Por sua vez, o artigo 3. define que "crime grave" é um delito transnacional por natureza e que envolve um grupo criminoso organizado (ibidem). Como bem resume Reginaldo Nasser, "grupos criminosos transnacionais podem ser definidos [...] como associações de indivíduos que operam de maneira transnacional com o fim de obter ganhos monetários, comerciais ou poder de influência, por meios ilegais em um ou mais estados nos quais atuam" (2014: 145). ${ }^{4}$

Em geral, esses grupos têm um alto grau de complexidade organizacional e profissionalização, com grande dispersão espacial e coordenação com outros grupos e atividades-meio - como o tráfico de drogas - para consecução de seus objetivos (Sain e Games, 2014: 121). Na verdade, a atuação do Crime Organizado Transnacional (COT) é apenas a ponta do iceberg, perante toda uma cadeia produtiva complexa e multifacetada. Em geral, essa cadeia se

\footnotetext{
${ }^{4}$ Hauck e Peterke (2010: 410) levantam uma crítica relevante sobre o conceito prevalecente de crime organizado. Segundo os autores, é difícil chegar a um consenso quanto "ao uso apropriado e ao significado da designação 'crime organizado'. Tem sido sugerido que este conceito, suspeito de constituir um veículo motivador de repressão ideológica junto de indivíduos e grupos sociais, um 'inimigo' artificialmente criado, mas de contornos mal definido, deve ser abandonado. Isto, no entanto, não tem acontecido”.
} 
inicia no nível local com o princípio da comercialização das "matérias-primas" (plantas como folha da marijuana e de coca, pessoas e armas), passa algumas vezes por intermediários do negócio (transportadores de pessoas e armas, laboratórios de produção de drogas, etc.) e ultrapassa fronteiras nacionais, até finalmente chegar ao comprador do "produto" ilegal. Este "produto" pode ser desde um ser humano traficado para trabalhos semelhantes a escravidão ou prostituição, a um entorpecente ou um explosivo para um atentado terrorista. Com o choque violento pelo controle de mercado entre competidores e vendedores nessas cadeias produtivas do crime - ou até mesmo como atividade-fim, no caso do terrorismo - surgem as estatísticas alarmantes de mortes resultantes de COT. ${ }^{5}$ Mesmo se concentrando em determinadas regiões, seria prematuro dizer que a problemática da violência ligada ao COT é algo focalizado em determinado canto do planeta (ver UNODC, 2010: 2). Como bem ilustra Jesse Banfield (2014: 8), embora a América Latina seja a zona mais profundamente afetada diante da grande concentração de homicídios violentos, a África também é afetada. O mesmo vale para a Ásia, que conta com uma rota de comércio de heroína que gera milhões de dólares americanos e permanece sob o controle de grupos armados unidos a políticos locais.

Adicionalmente, o fim da bipolaridade no sistema internacional proporcionou como resultado um contingente de milhares de homens armados com Kalashnikov's e Uzi's, cientes de seu poder e das possibilidades que se abriam para novos negócios. Nações com recente histórico de conflitos trazem consigo legados de instabilidade como grande volume de armas, quebra de laços sociais, deslocamentos internos e externos e grandes influxos para áreas urbanas (UNODC, 2013: 89). Essa conjuntura não tardou a dar as oportunidades para que um grande fluxo de pessoas entrasse na economia da droga, como visto com grupos criminosos na rota da heroína na Ásia Central, as Forças Armadas Revolucionárias da Colômbia (FARC), ou o Sendero Luminoso no Peru. Em outros cenários, como em Serra Leoa, na República Democrática do Congo e em Angola, o crime organizado e a violência política estiveram ligados ao contrabando de recursos naturais, como minérios e diamantes. Nos casos em que os antigos guerrilheiros deixavam as armas pacificamente através de acordos de paz, como visto na

\footnotetext{
${ }^{5}$ A título de exemplo, tais números podem ser vistos em especial na América Latina - região na qual a criminalidade organizada ganha força por inúmeros fatores como desigualdade social, rápida urbanização e altos níveis de pobreza (Ferreira, 2016b: 6). Apesar do crescimento de quase $20 \%$ na renda per capita nos últimos 20 anos, a taxa de homicídios permanece estática com uma média de 25 homicídios por 100000 habitantes (UNODC, 2011:35). Para além disso, 26 das cidades mais violentas do planeta estão na região, algumas delas com taxas de homicídio perto dos 80 por 100000 habitantes e com grande parte destas mortes relacionadas com o Crime Organizado Transnacional (Seguridad, Justicia y Paz, 2015, on-line).
} 
América Central, a dificuldade de serem inseridos na economia de mercado os fez voltar a pegar em armas, dessa vez para levar a cabo atividades ilícitas lucrativas.

Essa cadeia de violência movimenta um montante significativo de fluxos financeiros. A título de exemplo, segundo a United Nations Office on Drugs and Crime (UNODC), o COT nas suas mais diversas modalidades gera uma média de US\$ 650 bilhões anuais, ou 1,5\% do Produto Interno Bruto (PIB) mundial. Deste total, $92 \%$ dos fundos são lavados e $20 \%$ do montante estão ligados ao tráfico de drogas. Ainda, a grande parte do lucro dos negócios ilícitos se concentra nos Estados Unidos da América (EUA), Europa Central e Ocidental (UNODC, 2012: 9). Excetua-se aí a exportação anual de US $\$ 4,4$ bilhões em armas leves que, embora vendidas legalmente, são contrabandeadas para o cometimento de violência letal (Small Arms Survey, 2013: 180). Ainda que os números de mortes sejam difíceis de precisar, ${ }^{6}$ as poucas estatísticas disponíveis são impactantes e nos ajudam a ter um panorama do quão preocupante é o problema do crime organizado e os impactos que este gera para a promoção da paz em todos os níveis. Segundo o relatório Global Burden of Armed Violence 2015, publicado pela The Geneva Declaration on Armed Violence and Development, apenas 10\% das mortes violentas ocorrem em zonas de conflito armado, perfazendo um total de 70000 mortes de 2007 a 2012. No mesmo período, entre todos os homicídios, 75\% ocorreram de maneira intencional, perfazendo 377000 mortes relacionadas à violência interpessoal, violência entre gangues e crimes economicamente motivados (Geneva Declaration, 2015: 51-53).

Dentre as regiões do globo, América Central, Sul da África, América do Sul e Caribe lideram os números de mortes violentas (Jaitman, 2015: 4); porém, os homicídios ligados ao crime organizado são mais comuns nas Américas (Geneva Declaration, 2015: 75). O paradoxal nestes dados é que boa parte das Américas não se encontra em conflito armado regular - com exceção da Colômbia, que recentemente iniciou seu processo de paz - e, nos casos dos países que viveram conflitos e apresentam alto índice de violência, a grande maioria não está em guerra faz pelo menos uma década. Estes dados mostram a relevância em se considerar nas análises sobre paz e COT não apenas as zonas de conflito e pós-conflito, mas também a manifestação e as causas da violência em países de renda média como Brasil,

\footnotetext{
${ }^{6}$ Tal é a dificuldade de encontrar dados precisos, que essa tem sido uma preocupação das Nações Unidas. Em 2013, a Comissão de Estatísticas das Nações Unidas e a Comissão das Nações Unidas para Prevenção do Crime e Justiça Criminal acordaram em criar um projeto conjunto - e hoje em andamento - para melhora da qualidade e disponibilidade de dados estatísticos criminais (UNODC, 2013: 105).
} 
México e África do Sul. Em geral, comumente, os seus níveis extremos de violência são negligenciados pelos Estudos para a Paz (EP) ao analisar

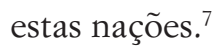

Nos cenários com forte atuação do COT, a paz ainda é um horizonte distante. Isto acontece igualmente em zonas de conflito, pós-conflito ou mesmo em países de renda média considerados "pacíficos". Nas zonas periféricas do Brasil, da Venezuela e do México, nas áreas rurais da Colômbia, nas florestas da África Central e em vilarejos próximos da produção de ópio na Ásia Central, a insegurança para a população é uma realidade constante. A presença da violência - seja ela direta, estrutural ou cultural - é um fator comum em todos estes casos. Grupos criminosos continuam a ameaçar, a extorquir, a tentar cooptar crianças e jovens para o crime e a eliminar quaisquer indivíduos que se coloquem no caminho dos seus lucros e objetivos de expansão. Assim, a conjuntura geral da atuação do COT e seus impactos na paz de milhões - talvez bilhões - de pessoas precisa ser examinada com mais pormenor, retomando criticamente os objetivos centrais dos EP. Isto implica que a compreensão das causas da violência deve ser objeto de atenção para o exame acadêmico de grupos que não são limitados por fronteiras, nem conflitos, nem regimes políticos.

\section{Conceitos de Estudos Críticos da Paz e Crime Organizado Transnacional}

Levando a cabo um "contínuo reexame crítico das categorias constitutivas e dos marcos conceituais de compreensão teórica, incluindo aí a construção histórica destes marcos" (Calhoun, 1995: 35), nota-se que importantes conceitos podem ser relidos criticamente quando se pretende compreender a espiral de violência gerada pelo crime. Neste debate crítico, um dos pontos de centralidade é a contínua significância do pensamento de Johan Galtung (Dahl, 2012: 258). Quatro de seus conceitos podem ser úteis para referência conceitual da relação entre Crime Organizado Transnacional (COT) e paz: paz positiva, violência direta, violência estrutural e violência cultural.

Como explanado anteriormente, a paz positiva em uma dada sociedade pressupõe uma ausência/redução de violência em suas três vertentes: direta, estrutural e cultural (Galtung, 1996: 9). Por sua vez, esta violência estrutural e cultural pode também ser compreendida como uma categoria analítica que estuda a maquinaria da opressão, seja ela material ou simbólica. Tais violências seriam resultado de muitas condições socioeconômica

\footnotetext{
7 Apenas um dado ilustrativo sobre o caso brasileiro: o país teve, entre 2001 e 2010, cerca de 500000 mortes violentas. No mesmo período, foram 400000 os mortos no Iraque, país que passou durante a década por uma intervenção estrangeira, violência sectária, terrorismo e fragilidade institucional (Waiselfisz, 2015).
} 
e culturalmente injustas, como são as formas de apagamento da memória e de dessocialização que impulsionam as condições destas estruturas (Farmer, 2004: 307). O continente americano é um caso que reflete este contexto de forma clara. Em um dos poucos estudos que examinam a categoria galtungiana de violência para compreender a criminalidade, Adam Blackwell e Paulina Duarte refletem que

a exclusão social encontra-se ligada a muitas das atividades criminais e problemas de violência que estão presentes na nossa região [Américas], incluindo os altos níveis de homicídios, sequestros e outros crimes, além de um desproporcional número de encarceramentos. Diante destas circunstâncias, a exclusão social se torna uma forma de violência estrutural e cultural que impede milhares de pessoas de alcançarem suas realizações pessoais. Esta violência estrutural afeta desproporcionalmente os membros mais vulneráveis da sociedade, tais como mulheres, jovens e minorias étnicas. (2014: 111-112)

O COT encontra, em sociedades em conflito, pós-conflito e até mesmo "em paz", uma massa de jovens desempregados, em sua maioria vivendo em regiões periféricas e num alto grau de pobreza, sendo constantemente vítimas de preconceito das elites da sociedade. Esse contexto acontece dentro de um marco definido, em que as tensões da sociedade reproduzem uma violência estrutural histórica permeada pela violência cultural de elites contra negros, indígenas, pardos e outras minorias. Não é surpresa notar que é justamente nas Américas que esse contexto é maximizado, encontrando no Crime Organizado Transnacional mais força e letalidade (Geneva Declaration, 2015: 75; UNODC, 2013: 13-15). Adicionalmente, a violência estrutural pode ser entendida, ao mesmo tempo, como uma categoria estruturada e estruturante. Ela teve gênese na sociedade e também estrutura e desencadeia novos processos violentos coletivamente criados que precisam ser analisados (ver Bourdieu, 1989: 18). Ou seja, não é somente uma guerra aos pobres, como afirma Gledhill (2015), mas também uma guerra estruturada pelos mais desfavorecidos envolvidos com a criminalidade. O crime organizado usa a estrutura de desigualdade que se manifesta como violência estrutural para parte da população, e simultaneamente reproduz essa estrutura violenta. Ele esgota o capital econômico e social que poderia ser utilizado para o desenvolvimento econômico e para melhorar a coesão social, trazendo instabilidade e, em alguns casos, até mesmo um retorno do conflito armado (UNODC, 2013: 77).

Somada à privação a que minorias e jovens pobres são submetidos, o resultado não poderia ser outro: o crescimento da criminalidade funciona 
dentro de um ciclo. Utilizando como exemplo as Américas, tal ciclo começa no produtor do insumo de uma droga, passa pela compra de armas ilegais, se utiliza da fragilidade das fronteiras para entrar em diferentes países e termina com o consumo de um novo viciado ou a morte de mais um jovem, fruto da violência estrutural a que se aliou a guerra do tráfico. Em outras regiões, a espiral de violência segue modelos similares, dependendo do agente e da estrutura. Isso abrange desde a população rural, que se vê envolvida na cadeia da heroína na Ásia Central, à mulher jovem de periferia da América Latina e do Leste Europeu que se vê vítima fácil do tráfico de pessoas, e até mesmo aos jovens negros sul-africanos e norte-americanos que lideram as estatísticas letais de cidades violentas como Joanesburgo, Detroit ou Chicago.

Em suma, a conceituação galtungiana de violência em seus três vértices, quando analisada à luz da problemática do COT, deixa de ser um mero conceito marginal - como tem sido a prática nos Estudos para a Paz (EP) convencionais. Eles passam a ser centrais para uma análise apurada de como o COT dissemina violência direta, é resultado de violência estrutural e ao mesmo tempo estruturador de violência. Assim, a violência estrutural e cultural se torna central não só para entender o fenômeno, como também como um resultado do fenômeno. Somente um exame apurado das condições de violência visível e invisível em que opera o crime poderá fornecer um panorama mais preciso do problema. Consequentemente, isso traz um outro debate central para uma abordagem crítica que relaciona EP e COT: o nível de análise em que o acadêmico deve operar sua investigação.

Quando analisarmos o fenômeno do crime organizado sem o termo transnacional, prontamente se poderá argumentar que o tema pode ser analisado sob um viés estatocêntrico - como é comum nos EP convencionais. Por exemplo, pode se investigar a atuação de um grupo criminoso como agente desestabilizador do Estado, ou como um elemento promotor da violência que dissemina o tráfico de armas, drogas ou uma rede de tráfico de pessoas e que, por consequência, pode gerar conflitos sociais. Ou seja, ele pode ser analisado como um mero problema de segurança nacional ou regional que afeta a paz ao disseminar a violência direta, aproximando-se assim muito mais de uma abordagem tradicional $^{8}$ de segurança do que uma calcada em valores de promoção da paz - como defende a gênese dos EP.

Tal abordagem seria uma contradição em si mesma. Primeiro, porque fragmenta a análise para o nível do Estado, quando na verdade o fenômeno é

\footnotetext{
${ }_{8}^{8}$ Para mais sobre o debate das diferenças entre estudos tradicionais e os críticos de segurança, ver Barrinha (2013).
} 
fluido, não respeita fronteiras, regimes políticos e se dissemina rapidamente através da tecnologia e organização. Segundo, porque os EP deixam de ser calcados em valores de defesa da paz como fim alcançável, para dar espaço a uma visão mais preocupada com a existência do Estado do que com as vidas ceifadas pela violência cotidiana.

Assim, neste debate sobre COT pode ver-se segurança como um conceito mais limitado que o de paz. Ao examinar a paz como ausência/redução de violência, presume-se que a violência é uma ideia abrangente que abarca desde a favela até ao campo de batalha; abrange tudo aquilo que impede a realização humana e que faz o ser humano ter menos do que pode ter. A ideia de violência não almeja ser um conceito utilitariamente prático nos dias atuais, mas sim dar uma perspectiva reflexiva e crítica para se pensar e investigar a paz (Galtung, 1972: 109).

Ao confrontar com outros trabalhos de explicação social sobre a paz, vemos que existem áreas cegas e mal-entendidos, quando analisamos o COT puramente sob o viés do Estado. Olhando por essa ótica, por exemplo, a América do Sul, com suas 28 cidades entre as 50 mais violentas do planeta, estaria em paz (Seguridad Justicia y Paz, 2015). Não haveria conflitos significativos entre Estados e por isso poderia se rotular a região como "zona de paz" - como feito por parte da literatura e criticado por Ferreira (2016b: 5-6). Dado que encontramos, no caso do COT, cenários que nem sempre se configuram como guerra no sentido tradicional do termo, seria igualmente inadequado pensar o conflito ou a guerra como nível de análise para compreensão da sua letalidade. Neste caso, pode se refletir sobre uma possibilidade analítica. Uma compreensão mais precisa do COT - tanto como resultado da estrutura como agente estruturante da violência - residiria em examinar a violência como unidade de análise. Isso implica investigar as causas desta violência em suas três vertentes acima explanadas, como ela se manifesta, e quais seus determinantes domésticos, regionais e transnacionais. Significa olhar para casos em particular e dissecá-los através de métodos focados como process tracing ou etnografia, para compreender como a violência nasce, se dissemina, vitima e, finalmente, poderia ser superada para uma benéfica promoção da paz positiva em um dado contexto social.

Isto não implica dizer que o Estado seja um ator irrelevante no que ao COT diz respeito. Ele é parte fundamental neste debate e continua a conjugar as instituições que podem lidar com o problema, seja através de medidas internas ou na construção de cenários cooperativos com outros Estados vizinhos e/ou distantes. O que não se pode, argumenta-se aqui, é cair na armadilha de crer que analisar saídas unicamente estatais constitui a resposta a um problema que é fluido e tem ramificações regionais e globais. Quando se coloca a violência 
como fator central de análise, as instituições que giram em torno dela deixam de ser o fim, para serem mais um ator para a sua explicação. Como já pressupunham Galtung (1996) e Wallensteen (2001), o foco deixa de ser uma análise dos impactos sobre o Estado, para dar lugar a um preciso exame da violência e suas consequências para a sociedade como um todo. Tal abordagem implica um esforço adicional para superar a fragmentação estatocêntrica, para aprender com múltiplas áreas do conhecimento, deixando de lado "concepções binárias de quantitativo/qualitativo, moderno/ pós-moderno, clássico/contemporâneo para se abrir a novos diálogos, insights e perspectivas em busca do objetivo último de compreender a paz como ausência/redução da violência de todos os tipos" (Ferreira, 2016a). É compreender que o crime organizado é transnacional, não respeita limites territoriais, é complexo, é multifacetado e tem múltiplas dimensões. Não obstante, reside nele um ponto em comum independentemente de onde opera e em que contexto (seja ele de conflito, pós-conflito ou países em paz): o COT é, ao mesmo tempo, um fenômeno fruto e disseminador de violência. Por fim, esta última é o núcleo pela qual o COT opera e na qual se pode compreender o seu impacto na busca da paz positiva.

\section{Considerações finais}

O presente artigo buscou examinar as possibilidades que os Estudos Críticos da Paz proporcionam para compreender o fenômeno do Crime Organizado Transnacional. Assim, ao invés de dar uma palavra final sobre a temática, ele visa oferecer um vislumbre do problema, um caminho para sua compreensão rumo à justiça social, à luz dos valores que fundamentam os EP. Ao mostrar o cenário geral dos impactos do COT na promoção da paz, nota-se que o fenômeno gera um índice de violência letal que hoje em dia supera largamente os conflitos regulares. Ao mesmo tempo, é uma temática pouco examinada e restrita muitas vezes aos estudos tradicionais de segurança e aos EP convencionais, focalizando a influência que esse gera na fragilização do Estado e na promoção de violência direta.

No entanto, mostramos aqui que uma análise crítica pode servir para entender o fenômeno de maneira mais precisa. O COT se configura como um desafio contemporâneo à paz, mas que não segue as prerrogativas de um conflito tradicional e é impulsionado de maneira ímpar pela globalização econômica e tecnológica. É um problema que não pode ser simplificado puramente numa abordagem repressiva e estatocêntrica, dado que é dinâmico, não respeita fronteiras e encontra raízes na desigualdade social. Por consequência, um cuidadoso exame dos marcos conceituais dos EP à luz da problemática e confrontando a literatura prevalecente, nos permite 
ver a importância da retomada da violência como conceituado por Johan Galtung enquanto núcleo analítico, assim como de uma releitura dos conceitos de violência estrutural e cultural para a compreensão do fenômeno.

Por fim, entende-se que o exame do COT - fenômeno que gera vítimas especialmente no Sul global - nos demanda a "aprender com o Sul" sobre seu sofrimento (Cravo e Pureza, 2005), identificando caminhos para que a paz positiva possa cada vez mais se tornar um horizonte alcançável. Finalmente, ainda que não tenha sido objeto deste trabalho, espera-se que essa reflexão teórico-conceitual abra a possibilidade do exame de outros conceitos dos ECP para a compreensão do COT. Por exemplo, as ideias de formação da paz (peace formation) - como construído por Oliver Richmond (2016) - podem ser aplicadas a contextos sem conflito regular e que não tenham passado necessariamente por guerras recentes, como é o caso do Brasil e da África do Sul? O exame crítico da paz liberal se aplica a contextos onde ela foi construída sem conflitos armados, como se vê nos sistemas econômicos injustos geradores de desigualdade no Sul global? Ou ainda, como podemos pensar emancipação local em um contexto de violência criminal generalizada? Estas são algumas questões em aberto que mostram a riqueza dos ECP, assim como a importância do seu resgate para compreender um mundo que quer ver paz onde esta ainda não existe, mas que pode construir paz através de categorias mais precisas e reflexivas.

\section{Referências bibliográficas}

Akinyoade, Demola (2012), "Ontology and Epistemology for Peace and Conflict Studies". Apresentado na International Conference on the Security Sector and Conflict Management, Institute of African Studies, Abadan, Nigeria, 14 a 16 de agosto.

Amaral, Rodrigo A. D. (2015), "Considerações sobre a violência pela ótica de Johan Galtung: alguns aspectos do terrorismo e o advento da intolerância", Cadernos de Campo: Revista de Ciências Sociais, 19, 101-116.

Banfield, Jesse (2014), Crime and Conflict: The New Challenge for Peacebuilding. London: International Alert.

Barrinha, André (2013), "Debates críticos: os Estudos de Segurança e o futuro dos Estudos da Paz e dos Conflitos”, Universitas: Relações Internacionais, 11(2), 1-8.

Battersby, Paul; Siracusa, Joseph M. (2009), Globalization and Human Security. New York: Rowman \& Littlefield.

Blackwell, Adam; Duarte, Paulina (2014), "Violence, Crime and Social Exclusion", in OEA - Organização dos Estados Americanos (org.), Inequality and Social Exclusion in the Americas: 14 Essays. Washington: OEA, 111-134 [2. ${ }^{a}$ edição]. 
Bourdieu, Pierre (1989), "Social Space and Symbolic Power", Sociological Theory, 7(1), 18-26. Calhoun, Greg (1995), Critical Social Theory. Cambridge: Blackwell.

Cockayne, James; Lupel, Adam (2011), Peace Operations and Organized Crime. London: Routledge.

Cravo, Tereza; Pureza, José Manuel (2005), "Margem crítica e legitimação nos Estudos para a Paz”, Revista Crítica de Ciências Sociais, 71, 5-19.

CS-ONU - Conselho de Segurança da Organização das Nações Unidas (2010), Statement of the President of the Security Council. S/PRST/2010/4, New York, 24 de fevereiro de 2010.

Dahl, Elisabeth (2012), "Oil and Water? The Philosophical Commitments of International Peace Studies and Conflict Resolution”, International Studies Perspectives, 14, 240-272.

Farmer, Paul (2004), “An Anthropology of Structural Violence”, Current Antbropology, 45(3), 305-325.

Ferreira, Marcos Alan S. V. (2016a), "A transdisciplinaridade nos Estudos para a Paz". Mundorama - Revista de Divulgação Científica em Relações Internacionais, n. ${ }^{\circ} 103$. Consultado a 04.06.2016, em http://www.mundorama.net/?p=19085.

Ferreira, Marcos Alan S. V. (2016b), “A contemporaneidade dos conceitos de paz e violência em Johan Galtung e sua aplicabilidade para a América do Sul”, in Erica Winand (org.), Defesa e segurança do Atlântico Sul VIII ENABED. Aracaju: UFS, 137-148.

Galtung, Johan (1969), "Violence, Peace and Peace Research”, Journal of Peace Research, 6(3), 167-191.

Galtung, Johan (1972), "Theory and Practice of Security", Instant Research on Peace and Violence, 2(3), 109-112.

Galtung, Johan (1990), “Cultural Violence”, Journal of Peace Research, 27(3), 291-305.

Galtung, Johan (1996), Peace by Peaceful Means: Peace and Conflict, Development and Civilization. London: Sage.

Geneva Declaration (2015), Global Burden of Armed Violence 2015: Lethal Encounters. Cambridge University Press: Cambridge.

Gledhill, John (2015), The New War on the Poor: The Production of Insecurity in Latin America. London: Zed.

Hauck, Pierre; Peterke, Sven (2010), "Organized Crime and Violence in National and International Law”, International Review of Red Cross, 92(878), junho 2010.

Imbusch, Pierre; Misse, Michel; Carrión, Fernando (2011), "Violence Research in Latin America and the Caribbean: A Literature Review", International Journal of Conflict and Violence, 5(1), 87-154.

Jaitman, Laura (org.) (2015), Los costos del crimen en la violencia y bienestar en America Latina y Caribe. Washington, D.C.: BID.

Jutila, Matti; Pehkonen, Samu; Väyrynen, Tarja (2008), "Resucitating a Discipline: An Agenda for Critical Peace Research”, Millenium - Journal of International Studies, 36, 623-640. 
Kemp, Walter; Shaw, Mark; Boutellis, Arthur (2016), The Elephant in the Room: How Can Peace Operations Deal with Organized Crime? New York: International Peace Institute, junho 2016.

Kuhn, Thomas (1998), A estrutura das revoluções científicas. São Paulo: Perspectivas.

Nasser, Reginaldo (2014), "Os Estados Unidos e o Crime Transnacional na América do Sul: aspectos históricos e contemporâneos”, in Reginaldo Nasser; Rodrigo Moraes (orgs.), Brasil e a segurança no seu entorno estratégico: América do Sul e o Atlântico Sul. Brasília: IPEA, 145-168.

ONU - Organização das Nações Unidas (2000), United Nations Convention against Transnational Crime and the Protocols Thereto. Viena: UNODC.

Patomäki, Heikki (2001), "The Challenge of Critical Theories: Peace Research at the Start of New Century”, Journal of Peace Research, 38(6), 723-737.

Richmond, Oliver; (2010), "Critical Peace and Conflict Studies", European Consortium for Political Research. Consultado a 04.04.2016, em http://standinggroups.ecpr.eu/cpcs/. Richmond, Oliver (2016), Peace Formation and Political Order in Conflict Affected Society. Oxford: Oxford University Press.

Ryan, Jordan (2013), "Conflict has changed, and this needs to be reflected in the future development agenda", UNDP, 2 de agosto. Consultado a 14.06.2016, em http://www.undp.org/content/undp/en/home/ourperspective/ourperspectivearticles/2013/08/02/conflict-has-changed-and-this-needs-to-be-reflected-in-the-future-development-agenda-jordan-ryan.html.

Sain, Marcelo; Games, Nicolas (2014), "Tendências e desafios do crime organizado na América Latina”, in Reginaldo Nasser; Rodrigo Moraes (orgs.), Brasil e a segurança no seu entorno estratégico: América do Sul e o Atlântico Sul. Brasília: IPEA, 119-144.

Seguridad, Justicia y Paz (2015), Most Violent Cities 2014. Mexico D. F.: Consejo Ciudadano para la Seguridad Publica y Justicia Penal.

Senehi, Jessica; Byrne, Sean (2011), "Where do we go from there?”, in Thomas Matyok; Jessica Senehi; Sean Byrne (orgs.), Critical Issues in Peace and Conflict Studies: Theory, Practice and Pedagogy. Plymouth: Lexington, 397-403.

Small Arms Survey - Graduate Institute of International and Development Studies (2013), Small Arms Survey 2013. New York: Cambridge University Press.

UNDP - United Nations Development Program (2013), Citizen Security with a Human Face: Evidence and Proposals for Latin America. New York: UNDP.

UNODC - United Nations Office on Drugs and Crime (2010), "The Globalization of Crime: A Transnational Organized Crime Threat Assessment”. Vienna: UNODC.

UNODC - United Nations Office on Drugs and Crime (2011), "Global Studies on Homicide 2011: Trends, Context, Data”. Vienna: UNODC.

UNODC - United Nations Office on Drugs and Crime (2012), "Estimating Illicit Financial Flows Resulting from Drug Trafficking and other Transnational Organized Crimes". Vienna: UNODC. 
UNODC - United Nations Office on Drugs and Crime (2013), "Global Study on Homicide 2013: Trends, Contexts, Data”. Vienna: UNODC.

Waiselfisz, Jacobo (2015), Mapa da violência: mortes matadas por armas de fogo. Brasília: Presidência da República.

Wallensteen, Peter (2001), “The Growing Peace Research Agenda”, Kroc Institute Occasional Paper \#21, Op.4. South Bend: Univ. of Notre Dame.

Wallensteen, Peter (2015), Quality Peace: Peacebuilding, Victory \& World Order. Oxford: Oxford University Press.

Wennmann, Achim (2015), "Crime and Conflict”, GSDRC Professional Development Reading Pack no. 12. Birmingham: University of Birmingham, março 2015.

Wiberg, Hakan (2005), "Investigação para a Paz: Passado, presente e futuro”, Revista Crítica de Ciências Sociais, 71, 21-42.

Young, Nigel (2013), “Concepts of Peace: From 1913 to the Present", Ethics \& International Affairs, 27(2), 157-173.

Zabyelina, Yuliya (2009), "Transnational Organized Crime in International Relations”, Central European Journal of International and Security Studies, 3(1), 11-22.

Artigo recebido a 25.08.2016

Aprovado para publicação a 12.01.2017

\section{Marcos Alan S. V. Ferreira}

Universidade Federal da Paraíba (UFPB), Centro de Ciências Sociais Aplicadas (CCSA)

Departamento de Relações Internacionais, Cidade Universitária, 58051-900 - João Pessoa, PB - Brasil

Contacto: marcosalan@gmail.com

\section{Critical Studies on Peace and Transnational Organized Crime}

This article aims to understand how key concepts in Peace Studies (PS), particularly its critical approach, can be useful in the analytical understanding of the ills inherent to Transnational Organized Crime (TOC). The article is structured in three parts. First, the differences between PS in its conventional and critical aspects is explored, followed by an analysis of

\section{Études Critiques de la Paix et Crime Organisé Transnational}

Cet article a pour but de mettre en lumière comment des concepts centraux des Études pour la Paix (EP), en particulier dans leur composante critique, peuvent être utiles en matière de compréhension analytique du fléau qu'est le Crime Organisé Transnational (COT). L'article est structuré en trois parties. Dans la première, nous nous penchons sur les 
TOC as a broad threat to peace that affects societies, be they in conflict or stable. Prior to the final considerations, the third part re-examines categories and conceptual frameworks of PS in the light of TOC, comparing other works and showing their limitations in understanding organized crime. This structure of reflection allows us to discuss critical analytical possibilities that encompass a consistent explanation of TOC in light of the conception of violence as proposed by Johan Galtung.

Keywords: drugs; illicit networks; organized crime; Peace Studies; violence. différences entre les EP dans leurs teneurs conventionnelles et critiques et, immédiatement après, nous analysons comment le COT représente une menace diffuse à la paix qui affecte des sociétés, tant au niveau des conflits que de la stabilité. Dans la partie qui précède les considérations finales, nous réexaminons certaines catégories et normes conceptuelles des EP à la lumière de la problématique du COT, en les confrontant à d'autres travaux et en démontrant leurs limitations quant à la compréhension du crime organisé. Cette structure de réflexion nous permettra de débattre des possibilités analytiques critiques qui comprennent une explication consistante de la problématique du COT à la lumière de la conceptualisation de violence proposée par Johan Galtung. Mots-clés: crime organisé; drogues; Études pour la Paix; réseaux illicites; violence. 
